\title{
The Effect of Pretreatment by using Electron Beam Irradiation On Oil Palm Empty Fruit Bunch
}

\author{
A. Kristiani ${ }^{{ }^{\star}}$, N. Effendi ${ }^{2}$, D. Styarini ${ }^{1}$, F. Aulia ${ }^{1}$ and Y. Sudiyani ${ }^{1}$ \\ ${ }^{1}$ Research Center for Chemistry, Indonesian Institute of Sciences \\ Kawasan PUSPIPTEK Serpong, Tangerang Selatan 15314, Indonesia \\ ${ }^{2}$ Center for Science and Technology of Advanced Material, National Nuclear Energy Agency \\ Kawasan PUSPIPTEK Serpong, Tangerang Selatan 15314, Indonesia
}

\section{ARTICLE INFO}

\section{Article history:}

Received 07 January 2015

Received in revised form 15 May 2015

Accepted 17 May 2015

\section{Keywords:}

OPEFB

Pretreatment

Irradiation

Physical properties

Chemical properties

\begin{abstract}
A B S T R A C T
Oil palm empty fruit bunch (OPEFB) is a potential type of lignocellulosic biomass for second-generation bioethanol production. The pretreatment process is an important process in the series of processes to produce bioethanol. This research aims to study the effects of pretreatment process by using electron beam irradiation to OPEFB's characterization as raw materials for the hydrolysis reaction to produce monomer sugars which will be fermented into ethanol. The untreated and treated OPEFB are characterized in terms of their physical and chemical properties. Analysis results of the compositional analysis by using NREL/TP-510-42618 method show that after pretreatment by using electron beam irradiation, OPEFB's total lignin content is changed little while its cellulose and hemicellulose contents tend to decrease with increasing irradiation dose. X-ray diffraction (XRD) analysis shows that there is a decrease of crystallinity compared to untreated OPEFB, except for 200-kGy irradiated OPEFB. The highest decrease of crystallinity was shown by 300-kGy irradiated OPEFB. Further, crystallite sizes of treated OPEFBs are not significantly different from the untreated, except for the 200-kGy irradiated OPEFB. Irradiation pretreatment also increases specific surface area, pore volume, and pore size. The IR spectra analysis show the absorption of cellulose, hemicellulose, and lignin.
\end{abstract}

(C) 2016 Atom Indonesia. All rights reserved

\section{INTRODUCTION}

More than 15 million ha land across the world is dominated by oil palm plantation, of which 5.37 million ha is located in Indonesia. Crude palm oil (CPO) is extracted from the fruit and the lignocellulosic waste remains as oil palm empty fruit bunch (OPEFB). Indonesia is one of the largest oil palm producers in the world, with its production reaching about 90 million metric tons of oil palm fruit in 2010, and resulting in about 20.7 million metric tons of OPEFB as a waste per year [1].

Lignocellulosic biomass consists of cellulose, hemicellulose, lignin, and inorganic materials [2]. Cellulose is a linear polysaccharide polymer of glucose consisting of cellobiose units. It occurs, among others, in combination with hemicellulose

\footnotetext{
${ }^{*}$ Corresponding author.

E-mail address: anis.kristiani@lipi.go.id

DOI: http://dx.doi.org/10.17146/aij.2016.472
}

and lignin linked together by complex inter- and intramolecular bonds forming a strong crystalline material named lignocellulose. Lignin is a substance with a very complex molecule consisting of phenylpropane units linked in a three-dimensional structure which is particularly difficult to biodegrade. There are chemical bonds between lignin, hemicellulose, and cellulose [3].

The properties of native lignocellulose biomass make them resistant to enzymatic attack. The aim of pretreatment is to enhance the digestibility of lignocellulosic materials [4]. The crystallinity of the cellulose, accessible surface area, protection by lignin and hemicellulose, and the polymerization degree and acetylation degree of hemicelluloses are the main factors affecting the rate of enzymatic degradation [5]. Cellulose microfibrils have both crystalline and amorphous regions, and the crystallinity is given by the relative amounts of these two regions. The major part of 
cellulose is in the crystalline form. Highcrystallinity cellulose is more resistant to enzymatic hydrolysis, and a decrease in crystallinity will increase the digestibility of lignocelluloses [6].

Several pretreatment methods of lignocellulosic materials are classified into physical pretreatments, physico-chemical pretreatments, chemical pretreatments, and biological pretreatments [7]. Physical pretreatments can increase the accessible surface area and size of pores, and decrease the cellulose crystallinity and polymerization degrees. Different types of physical pretreatment such as milling (e.g. ball milling, two-roll milling, hammer milling, colloid milling, and vibroenergy milling) and irradiation (e.g., by gamma ray, electron beam, or microwave) can be used to improve biodegradability of lignocellulosic waste materials. Iradiation technologies (especially electron beam irradiation) has been widely used for modifying the properties of materials [8]. This irradiation program aims to focus on the radiation-induced changes in the microstructural crystallinity of the substrates. Irradiation induces a chain cleavage mechanism by depolymerizing the polymeric material. Recently, an environmentally friendly electron beam irradiation (EBI) pre-treatment, which produces less inhibitory byproducts than the conventional thermochemical methods, was developed using a linear electron accelerator, and was subsequently evaluated with various analytical methods [9]. The electron beam technology has been widely applied in the properties of the polymeric materials [10]. Particularly, the mechanism of chain scission (by electron attacks) focus on changes (or degradation) in the structural crystallinity of substrates [11].

This research aimed to study the effects of electron beam irradiation pretreatment method to the characteristics of OPEFB in terms of chemical content, crystallinity, surface area, pore size, and pore volume.

\section{EXPERIMENTAL METHODS}

\section{Materials}

The OPEFB was obtained from PT. Perkebunan Nusantara VII (PTPN VII) in Palembang, South Sumatra.

\section{Irradiation pretreatment}

The irradiation was conducted using an electron beam machine, with dose variation from
$100 \mathrm{kGy}$ to $500 \mathrm{kGy}$ in $100 \mathrm{kGy}$ steps. The irradiation was carried out in the Center for Isotope and Radiation Application, National Nuclear Energy Agency, Pasar Jum'at, South Jakarta.

\section{Characterization of pretreated OPEFB}

X-ray diffraction (XRD) analyses were carried out for crystallographic phase identification of the catalyst samples using a Philips PW1710 diffractometer, with $\mathrm{Cu} \mathrm{K} \alpha$ irradiation at $40 \mathrm{kV}$ and $30 \mathrm{~mA}$, and a secondary graphite monochromator. Surface area, pore volume, and pore size were analyzed by using a Micromeritics TriStar II 3020 instrument. The chemical structures of the three components were analyzed using FT-IR spectroscopy in $\mathrm{KBr}$ phase using a Shimadzu Prestige-21 FT-IR spectrometer with ATR 4000 attached to an automatic data acquisition center.

\section{RESULTS AND DISCUSSION}

\section{Compositional analysis of OPEFB untreated and treated}

The OPEFB as a lignocellulose material consists of cellulose, hemicellulose, and lignin. The details of its chemical compound contents before and after treatment are shown in Table 1 .

Table 1. Chemical Compound Content of untreated and treated OPEFB

\begin{tabular}{lccc}
\hline \multicolumn{1}{c}{ Sample } & $\begin{array}{c}\text { Total } \\
\text { lignin } \\
(\%)\end{array}$ & $\begin{array}{c}\text { Cellulose } \\
(\%)\end{array}$ & $\begin{array}{c}\text { Hemi } \\
\text { cellulose } \\
(\%)\end{array}$ \\
\hline OPEFB untreated & 35.94 & 30.41 & 20.70 \\
OPEFB Irradiated 100 kGy & 35.40 & 32.31 & 22.21 \\
OPEFB Irradiated 200 kGy & 36.09 & 28.63 & 19.71 \\
OPEFB Irradiated 300 kGy & 35.66 & 28.92 & 20.00 \\
OPEFB Irradiated 400 kGy & 35.61 & 26.59 & 18.16 \\
OPEFB Irradiated 500 kGy & 36.71 & 24.35 & 17.12 \\
\hline
\end{tabular}

Table 1 shows that the chemical contents of the untreated OPEFB did not differ significantly from the irradiated OPEFB. The total lignin contents are similar for both samples while cellulose and hemicellulose contents tend to decrease by increasing irradiation dose. It can be explained by $\mathrm{X}$-ray diffraction (XRD) characterization which show that there are reductions of cellulose crystallinity as the irradiation dose is increased. The cellulose content measured by compositional analysis is crystalline cellulose; so, it is clear that 
cellulose content is decreased by increasing irradiation dose.

\section{X-Ray diffraction (XRD)}

The XRD pattern of untreated OPEFB compared to several irradiation-treated OPEFBs is shown in Fig. 1. The broad peaks at $2 \theta=17^{\circ}-19.9^{\circ}$ and $2 \theta=20^{\circ}-22.8^{\circ}$ indicate crystalline region. The $2 \theta=17^{\circ}-19.9^{\circ}$ region, which includes the $[-102]$ and [012] reflection peaks, corresponds to the cellulose region and the contribution of intramolecular scattering, while the $20^{\circ}-22.8^{\circ}$ region, which includes the [012] and [-303] reflection peaks, relates to the cellulose region and the contribution of intramolecular and intermolecular mixing dominated by intramolecular mixing. Pretreatments by using irradiation were aimed to decrease crystalline cellulose. The overall XRD pattern of $2 \theta=20^{\circ}-22.8^{\circ}$ which is crystalline cellulose belonging to irradiated OPEFB shows the decrease of crystallinity compared to untreated OPEFB, except for the 200-kGy irradiated OPEFB. The crystallinity of the 200-kGy irradiated OPEFB increases as indicated by the new reflection peak [050] at $2 \theta=44.74^{\circ}$, corresponding to crosslinking caused by rearrangement of cellulose molecules. The highest decrease of crystallinity is shown by the $300 \mathrm{kGy}$ irradiated OPEFB. The calculation of the crystallinity index will show this trend quantitatively.

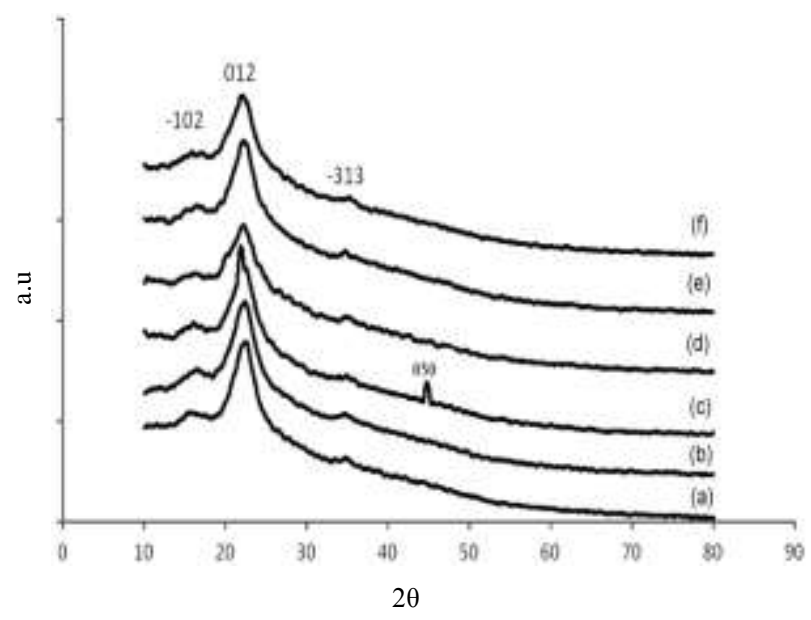

Fig. 1. (a) XRD Pattern of Untreated OPEFB, (b) Irradiated $100 \mathrm{kGy}$, (c) $200 \mathrm{kGy}$, (d) $300 \mathrm{kGy}$, (e) $400 \mathrm{kGy}$ and (f) $500 \mathrm{kGy}$.

Table 2 shows that the crystallinity of treated OPEFBs tends to decrease compared to untreated OPEFB, except for the 200-kGy irradiated OPEFB samples. The increase of crystallinity index in 200-kGy irradiated OPEFB can be explained based on XRD pattern. There is a slight increase in the degree of crystallinity for irradiation by over $200 \mathrm{kGy}$ due to the crosslinking taking place and the removal of the amorphous fraction (hemicellulose and lignin) [12]. Meanwhile, the crystallite sizes of the treated OPEFBs do not deviate considerably from that of untreated OPEFB, except for OPEFB treated by $200 \mathrm{kGy}$ of irradiation. There is a correlation between crystallinity index and crystallite size.

Table 2. Crystallinity Index of Untreated and Treated OPEFB

\begin{tabular}{lcc}
\hline \multicolumn{1}{c}{ Sample } & $\begin{array}{c}\text { Crystallinity } \\
\text { Index } \\
(\%)\end{array}$ & $\begin{array}{c}\text { Crystallite } \\
\text { Size } \\
(\mathrm{nm})\end{array}$ \\
\hline OPEFB untreated & 38.33 & 5.68 \\
OPEFB Irradiated $100 \mathrm{kGy}$ & 36.12 & 5.67 \\
OPEFB Irradiated $200 \mathrm{kGy}$ & 39.49 & 7.26 \\
OPEFB Irradiated $300 \mathrm{kGy}$ & 29.55 & 5.49 \\
OPEFB Irradiated $400 \mathrm{kGy}$ & 35.41 & 5.74 \\
OPEFB Irradiated $500 \mathrm{kGy}$ & 33.22 & 5.50 \\
\hline
\end{tabular}

\section{Surface area meter analysis}

Table 3 shows that pretreatment of OPEFB by using irradiation increases specific surface area, pore volume, and pore size. Specific surface area measured by this BET method is external specific surface area. Higher specific surface area will make contact between raw material and enzyme to be effective.

Table 3. Surface Area, Pore Volume and Pore Size of Untreated and Treated OPEFB

\begin{tabular}{lllc}
\hline \multicolumn{1}{c}{ Sample } & $\begin{array}{c}\text { Surface } \\
\text { Area } \\
\left(\mathrm{m}^{2} / \mathrm{g}\right)\end{array}$ & $\begin{array}{c}\text { Pore } \\
\text { Volume } \\
\left(\mathrm{cm}^{3} / \mathrm{g}\right)\end{array}$ & $\begin{array}{c}\text { Pore } \\
\text { Size } \\
(\mathrm{nm})\end{array}$ \\
\hline OPEFB untreated & 1.186 & 0.00043 & 2.0438 \\
OPEFB Irrad. 100 kGy & 1.7522 & 0.000579 & 2.0675 \\
OPEFB Irrad. 200 kGy & 2.1323 & 0.000713 & 2.0691 \\
OPEFB Irrad. 300 kGy & 2.1480 & 0.000745 & 2.0804 \\
OPEFB Irrad. 400 kGy & 1.9489 & 0.000675 & 2.0710 \\
OPEFB Irrad. 500 kGy & 2.1589 & 0.000751 & 2.0773 \\
\hline
\end{tabular}

\section{The FT-IR analysis}

Three three components of biomass consist of alkene, esters, aromatics, ketone, and alcohol, with different oxygen-containing functional groups observed, e.g., $-\mathrm{OH}, \mathrm{C}=\mathrm{O}, \mathrm{C}-\mathrm{O}-\mathrm{C}$, and $\mathrm{C}-\mathrm{O}-(\mathrm{H})$. Figure 2 shows that the most observed peaks in the spectrum originate from $-\mathrm{OH}$ stretching vibration (3100-3800 $\mathrm{cm}^{-1}$ ) and $\mathrm{CH}_{2}$ and $\mathrm{CH}_{3}$ asymmetric and symmetric stretching vibrations $\left(2800-3000 \mathrm{~cm}^{-1}\right)$. 
These vibrations were expected from hemicellulose, cellulose, and lignin. Intense peaks in the $1600-1700 \mathrm{~cm}^{-1}$ region originate from the stretching mode of carbonyls, mainly ketones and esters.

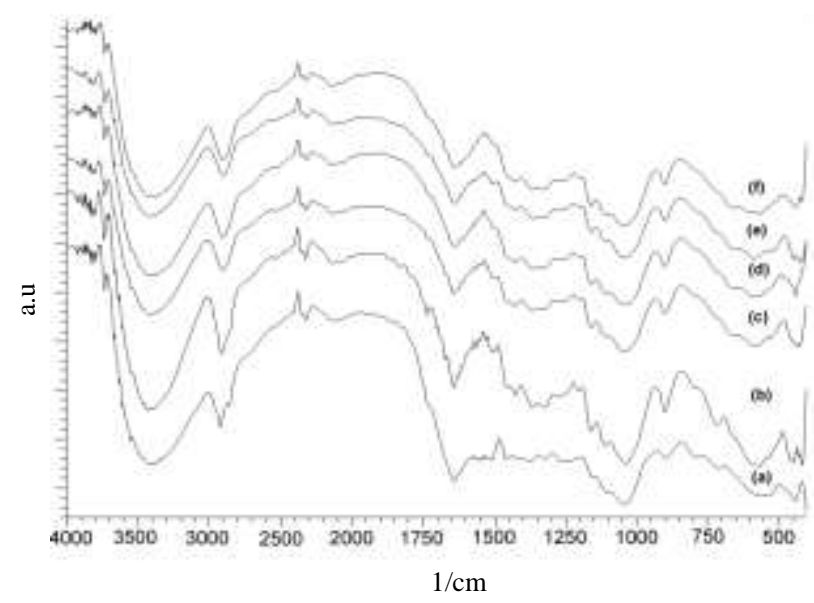

Fig. 2. (a) FT-IR Spectra of Untreated OPEFB (b) Irradiated $100 \mathrm{kGy}$, (c) $200 \mathrm{kGy}$, (d) $300 \mathrm{kGy,} \mathrm{(e)} 400 \mathrm{kGy}$ and (f) $500 \mathrm{kGy}$ respectively.

\section{CONCLUSION}

The pretreatment process of OPEFB by using electron beam irradiation reduced crystallinity, except for 200-kGy irradiation where crystallinity tends to increase due to the crosslinking taking place and the removal of hemicellulose and lignin (amorphous) fraction; and also extenuate physical and chemical properties of OPEFB in term of chemicals compound (lignin, cellulose and hemicellulose), crystallinity and crystallite size.

\section{ACKNOWLEDGMENT}

This work was fully supported by the
Ministry of Research, Technology, and Higher Education of Indonesia.

\section{REFERENCES}

1. Isroi, M.M. Ishola, R. Millati et al., Taherzadeh. Molecules 17 (2012) 14995.

2. M. Carrier, A. Loppinet-Serani, C. Absalon et al., Biomass and Bioenergy 43 (2012) 65.

3. A. Roy and A. Kumar, Journal of Emerging Trends in Engineering and Applied Sciences 4 (2013) 181.

4. V.B. Agbor, N. Cicek, R. Sparling et al.,. Biotechnology Advances 29 (2011) 675.

5. F. Monlau, A. Barakat, Trably et al.,. Environmental Science and Technology 43 (2013) 260. http://dx.doi.org/10.1080/ 10643389. 2011.604258

6. F. Monlau, C. Sambusiti, A. Barakat et al., Environmental Science and Technology 46 (2012) 12217. http://dx.doi.org/10.1021/ es303132t

7. P. Alvira, M. Tomás-Pejó and M. Ballesteros, Bioresour. Technol. 101 (2010) 4851.

8. G. Brodeur, E. Yau, K. Badal et al., Enzyme Research 2011 (2011) 1.

9. J.S. Bak, J.K. Ko, Y.H. Han et al., Technol. 100 (2009) 1285.

10. R.W. Hamm and M.E. Hamm Industrial accelerators and their applications. $1^{\text {st }}$ ed. World Scientific, Singapore (2012) 1.

11. J.S. Bak, Biotechnol. Rep. 4 (2014) 30.

12. M. Khalid, A.F. Ismail, CT. Ratnam et al., Radiat. Phys. Chem. 79 (2010) 1279. 